\title{
A strange hand: On self-recognition and recognition of another
}

\author{
Jenny Slatman
}

Published online: 14 April 2009

(C) The Author(s) 2009. This article is published with open access at Springerlink.com

\begin{abstract}
This article provides a phenomenological analysis of the difference between self-recognition and recognition of another, while referring to some contemporary neuroscientific studies on the rubber hand illusion. It examines the difference between these two forms of recognition on the basis of Husserl's and Merleau-Ponty's work. It argues that both phenomenologies, despite their different views on inter-subjectivity, allow for the specificity of recognition of another. In explaining self-recognition, however, Husserl's account seems less convincing. Research concerning the rubber hand illusion has confirmed that self-recognition involves more than an immediate experience of oneself. Merleau-Ponty's later work, describing self-recognition as the result of assimilative identification, will be used to explain the possibility of illusion between one's "hereness" and "thereness". The possibility of this illusion is inherent to self-recognition, while it is lacking in recognition of another.
\end{abstract}

Keywords Self-recognition · Recognition of another - Rubber hand illusion · Mirror image Identification

\section{Introduction}

When I shake another person's hand, I have no trouble differentiating myself and the other. ${ }^{1}$ At the same time, I perceive this other person as someone similar to myself, having similar capacities for perception and communication. This simple everyday event involves two forms of recognition: I recognize myself, distinguished from that which does not belong to me: and I recognize the other as a being who, like myself,

\footnotetext{
${ }^{1}$ My thanks to Monica Meijsing, Frans van Peperstraten, Karin de Boer, and to two anonymous reviewers for their constructive comments and helpful suggestions.

\section{J. Slatman}

Department of Health, Ethics and Society, Maastricht University, Maastricht, The Netherlands

J. Slatman $(\bowtie)$

Philosophy Department, Tilburg University, P.O. Box 90153, 5000 LETilburg, The Netherlands

e-mail: j.slatman@uvt.nl
} 
has a sense of herself and may be concerned for herself. It is no exaggeration to claim that nearly all human action and communication presuppose these two forms of recognition: self-recognition and the recognition of another. In this paper I would like to present a phenomenological analysis of the difference between these two forms of recognition.

To differentiate between these two forms of recognition I will focus on their perceptual organization, thus examining what the difference is between the perceptual experience of oneself and the perceptual experience of another. For the sake of clarity, I consider perception as an intentional act which correlates with an intentional object. This approach implies that I will not discuss forms of "primitive self-awareness", such as a mouse's awareness of itself and its own movement which prevents it from getting stuck in its mouse hole (Cf. Meijsing 1998, p. 136), or the experience of one's "bodily self" that may be immune "to error through misidentification" (Legrand 2006 citing Shoemaker 1968). In my view, a perceptual experience of oneself already involves identification with oneself. In self-recognition one experiences one's own body as an observational content, be it in a paradoxical way, since this kind of recognition - and this will be the main argument in this paper-implies both the experience of one's body as an intentional object (Körper) as well as the non-intentional experience of one's body as "lived through" (Leib).

Another preliminary remark I would like to make here is that, since I will focus on the difference between self-recognition and recognition of another, I will limit my analysis of recognition of another to a description of how a fellow human being appears to an individual's consciousness, and explore in what way this appearance differs from both one's own appearance as well as from the appearance of any perceptible object. To prevent gratuitous complications, I will not discuss phenomena that are normally related to "higher" forms of recognition of another, such as compassion, care or self-sacrifice. Despite the fact that perception of another may go together with these kinds of phenomena, we do not have to concentrate on the idiosyncrasy of something like care or compassion to understand the difference between self-recognition and recognition of another. Following, for instance, Husserlian vocabulary, we will see that the difference between various forms of appearance can be understood as a difference in intentionality, i.e. appresentation with or without the possibility of a primal presence (Urpräsenz).

It is true that in most cases, as in shaking hands, one does not confuse the perceptual experience of oneself with the perceptual experience of another. It may therefore seem pointless to explicate the difference between self-recognition and recognition of another. However, this difference is not always unambiguous. This is the case, for instance, in various illusions where it is possible to experience something as one's own body even if this is not the case. To illustrate this, I will refer in this paper to two illusions which are triggered by a certain twist in the incorporation of perceptual information: (1). The rubber hand illusion (RHI): this experimental illusion can be provoked by hiding a subject's hand (for instance behind a screen) and replacing it with a rubber hand, and subsequently touching simultaneously one's own hidden hand and the rubber hand. After a little while, subjects experience the rubber hand as if it were their own (Botvinick and Cohen 1998); (2). The illusion that one not only sees but also feels (certain parts of) one's own mirror image: for instance, while shaving their chin, some men not only feel the 
actual contact of the razor blade on their skin but also this part of their face in their mirror image (Ramachandran and Hirstein 1998, p. 1622).

Since these illusions seem to appeal to the idea that one can experience something strange as if it were one's own, it might seem plausible to consider the possibility of these illusions providing a possible foundation for recognition of another. Indeed, these illusions seem to refer to a certain Einfühlung. Armel and Ramachandran (2003), for example, conclude their study on the RHI with the suggestion that "understanding how we identify with external objects may also provide insight into the neural basis of empathy". In contrast with this suggestion, however, I will argue here that recognizing another person as similar to myself and recognizing a rubber hand as if it were my own are two different forms of recognition, although both involve otherness or strangeness.

To clarify the distinction between recognition of another and self-recognition, I will make clear that these two forms of recognition are based upon two different sorts of identification, or as I will term it, two kinds of "mirroring". Self-recognition is based upon a "narcissistic" identification, as is the case in being confronted with one's own mirror image. Recognition of another, conversely, implies a mirroring of goals and actions in a shared world. Whereas the first involves resemblance, the latter, which Husserl has called an unusual way of mirroring, does not imply resemblance.

My analysis involves a number of steps. I will begin by describing the difference between self-recognition and recognition of another as a difference between "hereness" and "thereness". Husserl's phenomenology will be my guide here, since he has made clear that the appearance of oneself implies a "zero-point", whereas the other appears always "over there". This clear-cut distinction, however, is not entirely satisfactory, since there are cases in which experiences of "thereness" and "hereness" cannot be sharply distinguished as in the RHI. On the basis of Merleau-Ponty's later philosophy, I will put forward the suggestion that self-appearance occurs at a chiasm of "hereness" and "thereness", whereas "the other", however close, only appears "there". It is the "thereness" that we share.

\section{Phenomenology of self-appearance}

As the body appears to oneself, it is an intentional object. It is a noema that correlates with a certain intentional act or a noese. At first glance, we can stick to an uncomplicated phenomenological model to describe self-appearance. For, indeed, one's own body can explicitly appear as an object to which certain qualities can be attributed; one can observe, for instance, the color and texture of one's own feet while cutting one's nails. Yet, if one's self-observation goes together with an explicit sense of ownership, it is not simply an intentional object. While perceiving my own body I may think "this is my body". However, the actual experience that this is my body involves more than an observational content. The experiential affirmation that this perceived body is mine is provided by non-intentional sensations.

One's own body can thus appear in two different modes: either as a thing or intentional object or as a localized lived-through experience of oneself. To explicate this difference I will make use of Husserl's analysis of Körper and Leib in his Ideas 
II (1952). However, unlike Husserl's own description, I will argue that in actual fact one cannot really separate these two forms of self-experience. Or, at least, it is not possible to experience one's own body only as Leib. Before discussing the Leib's impurity, I shall first briefly recapitulate Husserl's own view on the matter.

Husserl claims that if one touches one's left hand with one's right hand, the left hand can be experienced in two different ways. Firstly, it can be experienced as a thing with a certain extension and with certain properties. In this case, the left hand is the "physical thing left hand"; a Körper. It is the intentional correlate of the right hand's touching. But secondly, the left hand is also experienced as the localization of sensations (Empfindungen). The moment one touches one's left hand, one finds a series of touch-sensations (Tastempfindungen) in this hand, and since these sensations do not constitute physical properties such as smoothness or roughness, they do not constitute the physical thing "left hand". Rather, they constitute the experience that I feel in my left hand that it is touched.

Husserl coins the term Empfindnisse (sensings) to indicate these localized sensations. And it is by means of these Empfindnisse that the body as physical thing becomes the body as a Leib. I would call this the experience of "me-ness". The localized non-intentional sensations affirm that this is my body, whereas intentional sensations refer to an intentional object. In other words, the Empfindnisse constitute the body as one's own body, they form the sensory basis for the sense of ownership.

As opposed to the thinghood of the Körper, the Leib has a specific phenomenological meaning because of its typical spatiality. As is well known, the idea of adumbrations (Abschattungen) lies at the heart of the phenomenological theory of appearance. Phenomenal reality appears as a reality with real properties. It is not given at once; rather, it is always given through a manifold of adumbrations and sensuous schemes. This means that one and the same thing is presented in different horizons and perspectives, and that no single perspective can exhaust the possibilities of appearing. If we perceive, for example, a table, there is always one of its sides that we cannot actually perceive, and yet we still perceive one and the same table (Husserl 1950, p. 92-93). The perceived table is never fully present to consciousness: its rear sides are only co-present (or appresent). The same holds for one's hand. If one's left hand appears as the thing, "left hand," it appears through the constantly changing manifolds of adumbrations. The sensings (Empfindnisse) of one's left hand, however, are, according to Husserl, not given through adumbrations or schematization. One's body as one's own, as Leib, is given without any perspective, and is thus entirely present. Consequently, Husserl argues that the Leib bears in itself the "zero point" of all orientations. (1952, p. 166). Its spatiality is characterized as an "absolute here". I call this the Leib's "hereness".

The Leib is thus not an intentional object; rather it is pre-intentional, pre-objective or non-intentional, or even a "non-thing" (Waldenfels 1989). It is therefore not surprising that it is hard to find a proper translation of the German word Leib that emphasizes the lived-through experience of oneself instead of one's physical appearance. Translations like "lived through body" or "corps vécu" still connote thinghood (Depraz 1997). ${ }^{2}$ Despite its peculiar appearance, i.e. non-intentional and

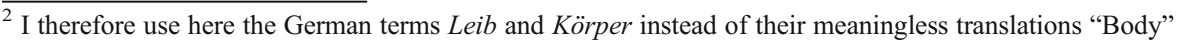
and "body", as used in the English edition of Ideas II.
} 
non-observational, Husserl claims that the Leib has a describable phenomenal reality, which is its capacity to be stimulated (Reizbarkeit). The animation of the body, the coming into being of a Leib, comes with the possibility of being stimulated (gereizt), or of being touched (Husserl 1952, p. 164).

I believe that this characterization of Leib immediately refers to its intrinsic relation with Körperlichkeit; for to have the possibility of being stimulated implies to be something touchable. As I see it, the Leib can only be touchable if we attribute extension and Körperlichkeit to it. It is true that one can also be touched or stimulated in a non-physical way, as is the case with emotions, ${ }^{3}$ but, according to Husserl's vocabulary, emotions do not constitute a Leib experience since they do not involve localized sensations. For Husserl, a Leib is constituted notably by the sense of touch, the sense of warmth, cold and kinetic sensation (p. 158). Hence, if we follow his idea that Leib consists of localized sensations and that its reality exists in the possibility of being touchable, we come to the conclusion that a pure Leib, i.e. a Leib separated from a Körper, does not exist. Leib therefore is a Leibkörper: it entails an experience of ownership as well as the experience of one's body as a thing, which is not necessarily experienced immediately as one's own. As Waldenfels (2000) accurately clarifies, the experience of Leib implies a relation to oneself (Selbstbezug): indeed one experiences oneself, but in this experience one does not coincide with oneself. And therefore this relation to oneself equally involves a withdrawal from oneself (Selbstentzug) and a relation to something strange or other (Fremdbezug). This Fremdbezug does not literally mean that one's own body is something strange, but rather it means that the affirmative experience of the owness of one's body - the experienced localized sensations in a presumed zeropoint without adumbrations-goes together with the appearance of one's body through adumbrations. This eventually implies the experience of co-presence of one's own body, instead of its being fully present, as Husserl would have it.

To phrase it differently, since the Leib cannot be experienced without adumbrations, it is not only "here", but also "there". Husserl did not discuss this aspect. In fact he seems to exclude the idea of the "thereness" of one's own body, while arguing that visual sensations are not attributable to the constitution of Leib. He claims that one cannot see oneself seeing in the way one can touch oneself touching. To see oneself seeing, one needs a mirror, and this reflected seeing of one's own seeing does not have the same directness as the touching of touching. Seeing my own seeing eye in the mirror cannot be distinguished from seeing someone else's seeing eye (Husserl 1952, p. 155). He therefore concludes that vision does not constitute a genuine sense of bodily ownership. "The Body (Leib) as such can be constituted originarily only in tactility and in everything that is localized with the sensations of touch" (Husserl 1952, p. 158).

It might be true that vision and touch are clearly distinguished sensory modalities, and that they are based upon different forms of feedback or reflection, however, Husserl seems to overlook the fact - or at least, he does not discuss it - that the sense of bodily ownership most of the time is not based upon a single sensory modality. In our daily experience of ourselves, visual perception is not excluded from our sense of self. Quite the contrary, if visual perception is at stake it integrates in a powerful

\footnotetext{
${ }^{3}$ I would like to thank an anonymous referee for this objection.
} 
way with tactile perception and proprioception. As the example of the rubber hand illusion shows, multisensory integration can result in a disruption of proprioception. This illusion teaches us that self-recognition, unlike Husserl's description of it, is not only based upon an immediate, felt, localized sensation in a zero-point or "hereness", but that it may also involve the "thereness" of what is seen.

\section{The rubber hand illusion}

The rubber hand illusion is an experimental illusion which can be generated relatively easily in normal individuals. A dummy rubber (left) hand is placed in front of a subject on a table, while the subject's own (left) hand is placed behind a screen so she cannot see it. The experimenter strokes both (left) hands synchronically with a brush. After a while, the subject experiences the tactile sensations as arising from the rubber hand. Botvinick and Cohen (1998) were the first to examine this illusion. They found that the majority of tested subjects experienced the touch of the brush on the spot where they saw the rubber hand being touched. They also felt as if the rubber hand were their own. Botvinick and Cohen claim that this illusion occurs because of a "three-way interaction" between vision, touch and proprioception. Further research of the RHI, by means of fMRI brain-scans supports the thesis that the sense of body ownership requires multisensory integration or interaction (Ehrsson et al. 2005; Ehrsson et al. 2004).

Sense of body ownership thus presupposes the integration of intermodal sensory information. But the integration of various sensory stimuli is not specific to this experience. Botvinick (2004) claims, for instance, that the phenomenon of ventriloquism is also based upon familiar multisensory integration (visual and auditory), while this illusion does not involve the sense of bodily ownership. Another prerequisite for self-attribution is the synchronicity of sensory stimuli. If the brush strokes on the rubber hand and one's own hand are not synchronized, the illusion decreases or fades away. Synchronicity of input is also present in ventriloquism. There should thus be yet another precondition which is specific for the sense of bodily ownership. I would call this a top-down identification process. I will now discuss two studies on the RHI that agree about the importance of multisensory integration and synchronicity of sensory input, but disagree about the necessity of a top-down identification process in the sense of bodily ownership.

Armel and Ramachandran (2003) suggest that the effect of synchronized sensory information is so strong that one can also attribute to oneself objects that do not visually resemble one's own hand. They tested what happened when a table was synchronously touched with one's own hidden hand. It appeared that in touching the table some subjects felt as if the table were part of their own body. Illusionary selfattribution can thus be seen to occur with objects that do not resemble the hand, although less intensively so than with the rubber hand. Armel and Ramachandran therefore maintain that the bottom-up process (i.e. the process of integration of sensory information) seems to be resistant to top-down knowledge about one's own body. Even if you know that it is totally absurd for the table to be part of yourself, you still experience it as such. 
Tsakiris and Haggard (2005) contradict this view. They tested the RHI while (a) varying the position of the rubber hand, and (b) replacing the rubber hand by a wooden stick. They established that in (a) the illusion was remarkably decreased when the rubber hand was placed in an incongruent position with respect to one's own hand, and that in (b) the illusion had virtually disappeared when a wooden stick replaced the rubber hand. From these observations they infer that a bottom-up process is not sufficient for self-attribution. The multimodal sensory input needs to be integrated within a certain representation of one's own body. According to them, self-attribution thus also requires a top-down process.

As I see it, the contrast between these two views on the RHI is first of all due to different descriptions of embodied self-experience. Armel and Ramachandran use the term "body image" when they refer to the experience of one's own body. They support the idea that one's body image is a construct in the brain, the result of the way in which (bottom-up) specific sensory information is integrated. Although Ramachandran and a colleague in another study claim that the body image also implies "a stable internal mental construct of a unitary corporeal self that endures in time" (Ramachandran and Hirstein 1998, p. 1622), in their RHI study they underline that "despite its appearance of durability", one's body image can be "easily and profoundly modified" (Armel and Ramachandran 1504). They claim that it is nothing but a "temporary shell" (p. 1506). For them "body image" equates the neuronal map or the cortical representation of the body. This, I think, is a rather limited interpretation of body image.

Armel's and Ramachandran's neuronal conception of body image is problematical since it does not take into account that the temporary illusion takes place against the background of a more stable experience or idea of oneself. In fact, the idea of body image as a mere temporary, instantaneous shell cannot provide an explanation for the fact that subjects in the RHI-experiment experience the rubber hand as if it were their own; they know that it is an illusion, and thus they can interpret the experience of the RHI against the background of their "normal" sense of bodily ownership. Armel and Ramachandran seem to suggest that such a normal sense of body ownership is not fundamental while claiming that the synchronicity of sensory input can even result in the experience of illusionary tactile sensations in a table. But then again, they fail to explain why the illusion is far less strong with a table than with a resembling rubber hand in a congruent position. This is only possible if the experience of the RHI or the experience of the illusionary tactile sensations in a table is related to preceding embodied self-experience. I therefore adhere to Gallagher's description of body image as a "system of perceptions, attitudes, and beliefs pertaining to one's own body" (2005, p. 24). This system not only involves current perceptions or current conscious awareness; it also implies "sets of beliefs, attitudes, or dispositions" (p. 25). The RHI may trick the brain and cause a change in neuronal maps; it does not completely transform one's body image.

Tsakiris and Haggard are not always very consequent and clear in their terminology: sometimes they use the term "body representation" and sometimes "body scheme" while referring to the experience of one's body. I think that the usage of the term "scheme" is not entirely adequate here, since "body scheme" involves a "system of sensory-motor capacities that function without awareness or the necessity of perceptual monitoring" (Gallagher 2005, p. 24) instead of a representation of the 
body. This confusing usage of the term "body scheme" might also be the reason that Tsakiris and Haggard equate the incorporation of tools with the attribution of the rubber hand to one's own hand (p. 80, 90). They therefore claim that the RHI can be explained in terms of an extension of one's body scheme. I do not find this explanation entirely convincing and believe that there is an essential difference between the RHI and the incorporation of tools; for one does not "feel" illusionary tactile sensations in a hammer while having "incorporated" it. Moreover, if we focus on the incorporation of artificial limbs, we can make yet another phenomenological distinction which requires a more subtle idea of body scheme extension, i.e. the distinction between feeling an artificial limb as part of one's body and experiencing it only as an enabling and valuable tool (Murray 2004). Despite their confusion on this point, I think that Tsakiris' and Haggard's explanation of the RHI entails an important argument. They claim that the process of self-attribution requires a topdown mechanism and this originates from "the representation of one's body". According to them, one can only attribute something to oneself if one already has a certain representation of oneself. In a later study, in which more attention is paid to the difference between body image and body scheme, Costantini and Haggard (2007) confirm that perception of current sensory stimulation involves assimilation to a "pre-existing internal representation of the body", including its own frame of reference (p. 238). This assimilation process, which is lacking in Armel's and Ramachandran's explanation, in fact, implies a process of identification.

As I see it, self-recognition is only possible on the basis of an identification process. Because of this Armel and Ramachandran's conception of body image can do no justice to the particularity of self-recognition. Their idea of body image, as an ongoing process of correlating sensory input, cannot explain what it means to recognize oneself, because such a process requires two poles: I recognize myself. To phrase it differently, recognition implies identification of two poles: $\mathrm{X}=\mathrm{Y}$. Armel's and Ramachandran's conception does not fit into this model. Their idea of body image could be symbolized as $\mathrm{x}+\mathrm{x}+\mathrm{x}=\mathrm{X}$ (in which " $\mathrm{x}+\mathrm{x}+\mathrm{x}$ " refers to integration of sensory input and " $\mathrm{X}$ " to body image). The sense of body ownership which is at stake in the RHI may be supported by a temporary change of one's neuronal map, but the fact that one attributes the rubber hand to oneself presupposes something else than the brains' capacity to detect statistical correlations in sensory input. Tsakiris' and Haggard's explanation of the RHI, by contrast, suggests that self-recognition involves a process of identification between an already existing representation of one's body and something else. This could be symbolized as "rubber hand" = "my body according to an already existing representation", or $\mathrm{X}=\mathrm{Y}$.

In the case of recognition of another, one also "identifies" with someone outside oneself. This form of recognition indeed means an (immediate) sense of the presence of someone similar to oneself. In empathetic forms of recognition of another one can even sense or imagine what someone else may feel, which enables compassion with this person. Sensing another's feelings, however, is distinguished from sensing oneself since empathetic feelings do not result in self-attribution: even if I "feel" my son's pain, I would still experience him as another person. Self-recognition and the recognition of another may be difficult to distinguish in (pathological) cases in which people have the experience that they are intruded upon by someone else, as some schizophrenics do. However, even in these cases, one can make a distinction 
between self-recognition and recognition of another. Indeed, the very fact of an experience of something strange in oneself still presupposes a distinction between a sense of oneself and a sense of something strange. If this were not the case, one would not be able to experience something strange as strange. It is therefore argued that schizophrenia involves a disruption in the sense of agency-the sense that one is the source of an action, voice or a thought — but not in the sense of bodily ownership (Gallagher 2005, p. 174). Hence, even in schizophrenia, in which another's otherness has come unpleasantly close to oneself, one can still make a distinction between self-recognition and recognition of another.

I would call the identification which is at stake in the recognition of another a weak form of identification. This kind of identification does not involve $X=Y$, as if the other is experienced as part of oneself, rather it implies $\mathrm{X} \neq \mathrm{Y}$. To explain the latter form of identification, I will now draw on Husserl's theory of appresentation in which he maintains that recognition of another involves a typical form of intentional consciousness.

\section{Appresentation and recognition of another}

Husserl's notion of intersubjectivity is determined by his theory of perception, which is based on the idea of adumbrations (Abschattungen) and horizontality. In his fifth Cartesian Meditation (1931), Husserl explains that intersubjectivity is a necessary condition for the constitution of the world, for the existence-sense (Seinsinn) of the world includes "thereness for everyone" (das Für-jedermann-da). Without (imaginative) others the world would be literally senseless. The relation between this "thereness for everyone" and horizontal intentionality becomes immediately evident if we look again at the example of the perceived table. While perceiving a table, I perceive it from a certain perspective. Changing the perspective will not result in the constitution of another table. The table appears as one and same table despite the manifold Abschattungen, adumbrations (Husserl 1931, p. 93). Perception of the table is more than the sum of my perspectives. Therefore, perception is always linked to a certain horizon, which entails other possible perspectives. Horizontal intentionality already involves intersubjectivity (Zahavi 1997). To put it simply, the relation between I and other should be understood from the fact that we share a world. ${ }^{4}$

Let us now examine in what sense recognition of another involves a typical kind of consciousness and is hence distinguished from consciousness of oneself. It is well known that Husserl borrows the term "empathy" (Einfühlung) from Theodor Lipps. Like Lipps, Husserl criticizes the idea that the recognition of other people is based upon a theoretical analogy inference (Analogieschluss) as was put forward, for instance, by Erdmann. According to this latter view-which revisits Descartes' idea of perceiving other people - one does not really experience a relation between the other's body (Körper) and her lived through experience (Leib), but one logically infers this relation from one's own experience of it. Opposed to this view, Lipps

\footnotetext{
${ }^{4}$ Zahavi (2001) has therefore argued that a face to face encounter is not the most fundamental form of intersubjectivity. We could say that transcendental intersubjectivity provides the condition of possibility to perceive and explore the world.
} 
claims that recognition of another is based upon an immediate experience of another. Also criticizing this idea, Husserl's position is in between these two opposites: recognition of another is neither based upon inference nor upon an immediate experience. It is rather based upon the mediate experience of another (Depraz 1995, p. 165). Husserl thus maintains that Einfühlung is a form of apperception. And, according to his terminology, apperception is not a "thinking act", but rather a perceptual act by means of which we grasp the sense of something new, since this sense refers back to a "primal instituting" (Urstiftung) in which a thing with a similar sense was constituted for the first time (1931, p. 111).

By the same token, we apperceive others. The apperception of others is called "pairing" or "coupling" (Paarung) (p. 112). Unlike the apperception of unknown things this "pairing" refers back to a primally institutive original which is always livingly present (i.e. the ego). Here we find a first indication of differentiation between the experience of oneself and the experience of another. Whereas my own body $(L e i b)$ is apperceived in an original and immediate way, the apperception of another is not original and not immediate. This means that the other is never fully present to one's consciousness. This again, can be explained by means of Husserl's theory of perception. What is actually present to my consciousness when I perceive a table are the impressions connected to my actual perspective: its rear sides are not originally present to me. The actual presence of impressions is called Urpräsenz but perceptual intentionality nonetheless also directs at rear or invisible aspects. Indeed, we perceive a table (including its rear) and not a sum of sensory impressions. Intentional consciousness thus immediately exceeds the content of what is actually given. It makes co-present (mitgegenwärtig machen) what is not originally present. This is called Appräsenz, Kompräsenz or Kompräsentation and was later replaced by the term Appräsentation (Husserl 1973a, p. 23-24). Here I use the translation "appresentation".

Intentionality as appresentation forms the basis for recognition of another. One might want to object that this equalizes recognition of another and perception of external objects. Husserl emphasizes, however, that there is a crucial difference: appresentation in perception of external objects can turn into original presentation. Standing in front of the table, the underside is appresented to me. Lying on my back under the table this side becomes originally present. Such changes of perspective will not have the slightest influence on the apperception of the other, since any original presentation is excluded here a priori (1931, p. 109). One could say that the making co-present in perception of external objects is always related to the original presentation of its front sides, whereas the making co-present of the other cannot be related to anything present. Pairing is thus the typical appresentation that joins up what is principally absent and what is present.

According to Husserl, the perception of external objects implies transcendence, i.e. the sense of the world includes its being outside consciousness. The table I perceive is a transcendent object for me. Since this transcendence is related to originally present impressions that form the hylè, the immanent constituent of consciousness, it is transcendence in immanence. The appearance of the other also implies transcendence. But this transcendence is not related to immanence; no single aspect of the other's lived through experience is originally present to me. Exceeding the original sphere of consciousness, recognition of another therefore entails the 
most proper (echt) and genuine (wahr) form of transcendence (Husserl 1973b, p. 442). It is a form of intentionality that directs at "alterity" (Cf. Depraz 1995). The question is how something genuinely transcendent can appear to me as something I immediately recognize as akin to myself?

It is by way of mirroring (Spiegelung) and analogue (Analogon), though not in the habitual sense (gewöhnliche Sinne), that the other appears to me (Husserl 1931, p. 94). The appresentation of another is mainly constituted by the experience of her "changing but incessantly harmonious 'behavior' (Gebaren)" (Husserl 1931, p. 114). The physical side of one's behavior is actually present to me, and through it I can appresent something psychic. Recognizing another thus mainly results from recognizing her actions and not just her physical appearance.

Petit (2003), interpreting Husserl's theory of constitution, has argued that the "neural correlate of the noema other" is formed by so-called mirror neurons. Without digging into the details of current neuroscientific research about these neurons, it is indeed interesting to see to what degree Husserl's theory on Einfühlung is congruent with hypotheses that some contemporary scientists have brought forward after the discovery of mirror neurons in the 1990s. Mirror neurons are neurons that are activated when one performs a certain action while observing someone else perform this action (Gallese et al. 1996). These neurons thus mirror the observation and performing of actions, thus triggering an immediate understanding of another's action, without needing a translation from perceived action into performed action. This intersubjective understanding should not be interpreted as a form of (automatic) simulation, but rather as an immediate perception of the meaning of another's action or gesture (Gallagher 2007)..$^{5}$

If it is true, as Petit claims, that the neuronal correlate of Husserl's "other" is formed by mirror neurons, I would say that these neurons indeed mirror in a nonhabitual way, not providing resembling mirror images as normal mirrors do, rather, enabling mirroring oneself with another. Husserl writes that the mirror neither implies confusion between ego and alter ego, nor reciprocity between Leib and Körper. I thus do not have immediate access to the other's psyche or her subjective experience of being a living body (Leib). Her Leiblichkeit can never be originally present to me. If that were the case she and I would be one and the same:

Experience is original consciousness; and in fact we generally say, in the case of experiencing a man (ein andere Mensch): the other is himself there before us 'in person'. On the other hand, this being there in person does not keep us from

\footnotetext{
${ }^{5}$ Mirror neuron activity has been observed first of all in intentional actions, such as, grasping an object with one's hand (Rizzolatti et al. 2000). Interestingly, they can also be activated by the observation of touch, which may provide us with an implicit and immediate understanding of touch (Keysers et al. 2004). Because of this, one may suspect that they could also be active during self-recognition in case of the RHI, which is indeed one of the concluding suggestions of Armel and Ramachandran (2003, p. 1506). I think, however, that the possibility of the RHI is not simply the result of mirror neurons that enable a certain Einfühlung, or immediate sense of another's being touched. As I see it, mirror neurons seem to support an immediate understanding of another; one immediately understands, without reflection or comparison, another's actions, emotions or feelings. I would therefore say that mirror neurons have to do with our most basic form of "social cognition". The RHI, by contrast, does not appeal to any kind of sociality: even if it were possible to re-arrange the experiment in such a way that one does not use a rubber hand, but the hand of another human being, the fact that this hand of another person could be experienced as if it were one's own would have nothing to do with social cognition or recognition.
} 
admitting forthwith that, properly speaking, neither the other Ego himself, nor his subjective processes of his appearances themselves, nor anything else belonging to his own essence (Eigenwesen), becomes given in our experience originally. If it were, if what belongs to the other's own essence were directly accessible, it would be merely a moment of my own essence, and ultimately he himself and I myself would be the same" (Husserl 1931, p. 108-109).

Although Husserl uses the term "pairing", which might suggest a certain amalgamation of I and other, it is essential to underline that his theory of recognition of another is based upon the radical phenomenological difference between experiencing oneself and experiencing another. The alter ego is not me; it is another (than) me. The mirror generates a gap between "here" and "there". This nonreducible distance is essential to the (genuine) transcendence of the other. Whereas my own Leib appears according to the mode "here", another Körper always appears "there" (Husserl 1931, p. 119). Husserl's theory of intersubjectivity eventually leads to the conclusion that recognition of another refers to "thereness", whereas selfrecognition implies "hereness".

I believe that Husserl's description of recognition of another based upon an unbridgeable transcendence or "thereness" is convincing. However, his idea that self-recognition involves only an experience of Leib in a localized zero-point needs reconsideration. Indeed, the possibility of an illusion such as the RHI makes clear that in self-recognition both "here" and "there" are at stake.

To explicate the thereness in self-recognition, I would like to refer here to a comparable illusion which has been described by Paul Schilder (1935). He conjures up the example of someone holding a pipe or pencil in front of a mirror. When pressing the fingers, one can clearly experience that the sensations of pressure are not only felt in one's own hand but also in the hand in the mirror. This is, in fact, the same kind of confused feeling some men may have when they shave their chin while watching their mirror image: some "feel" the razor blade on their face in the mirror, as described by Ramachandran and Hirstein (1998).

Although mirror-image-illusions are stimulated by one's own body whereas the RHI is provoked by an external source, they constitute the same kind of experience and are thus, at a phenomenological level, similar. Both in the RHI and the mirrorimage-illusions tactile sensations are experienced in a body part that is seen. They are both about a confusion in location due to the manipulation of the correlation between visual and tactile sensations. Also, in neuroscientific studies, one does not seem to make a difference between the RHI and the mirror-image-illusions. Ramachandran and Hirstein (1998), for instance, call them all "phantoms in normal individuals", which, at a neuroscientific level, are even comparable with the illusion of the (pathological) phantom limb. I would say that both kinds of illusions are essentially about the experience of one's own body's location as both "here" and "there". Schilder subsequently suggests that the recognition of one's own "thereness" in one's mirror image may make comprehensible the recognition of another's "thereness":

The experience of the sensation in the mirror is as immediate and original as the experience in the real hand. It is at least very probable that parts of these experiences are given when we see the bodies of others, especially when one 
considers how little the optic experience concerning one's own body image differs from the experiences we have concerning the optic image of the bodies of others (Schilder 1935, p. 224).

Although I believe that intersubjectivity is about sharing "thereness", I would not say that the experience of one's own "thereness" in one's mirror image can be directly related to the "thereness" of (visible) others. We do share visibility, but in the case of "feeling" one's own mirror image, one's visual appearance goes together with localized illusionary tactile sensations, whereas the visual appearance of another may arouse all kinds of empathetic feelings, but no localized illusionary tactile sensations. We should therefore differentiate between the "thereness" of another and the "thereness" of one's own mirror image. The alter ego is not just simply the same as my mirror image. To explain this we need to go one step further and develop the idea of self-recognition based upon "hereness", which is distinct but still inseparable from "thereness".

\section{Appresentation in self-recognition}

To understand in what sense recognizing one's mirror image differs from recognizing another human being, we need to examine what Husserl means exactly when he says that the "mirroring" involved in recognition of another is not habitual. Depraz (1995, p. 165) claims that this implies an abandoning of the idea of analogy based upon resemblance. I think that this is a classification which is helpful in understanding this uncommon mirroring: recognition of another is not based upon a resemblance between us, as if we were each other's mirror image. I will elaborate on the difference between resembling and non-resembling mirroring while focusing on the process of identification that is involved. The appearance of the other differs from the appearance of one's own mirror image because of a difference in identification. I believe that this difference can be articulated on the basis of some aspects of Merleau-Ponty's later work.

At one place, Merleau-Ponty refers explicitly to Schilder, while discussing the function of the mirror (1961, p. 129). While mentioning the example of the man with a pipe standing in front of a mirror, Merleau-Ponty emphasizes the fact that the mirror externalizes or extends my body, my "here', in the world over "there" while stating: "The mirror's phantom draws my flesh into the outer world (traîne dehors ma chair), and at the same time the invisible of my body can invest its psychic energy in the other bodies I see" (129-30).

Merleau-Ponty's interpretation of the mirror stage, i.e. recognizing one's own mirror image, is, to a certain extent, comparable to Lacan's interpretation. Lacan (1949) has argued that the recognition of one's own mirror image implies immediately a misrecognition (méconnaissance) since the image is not the same as oneself; it is an externalization or alienation of oneself. Merleau-Ponty (1951) subscribes to this viewpoint when he explains the psychological transformation at stake for an infant in the mirror stage as a passage from the interceptive me ( $\mathrm{moi}$ ) to the visual, specular I (je): "I am no longer what I felt myself, immediately to be... I am torn from myself, and the image in the mirror prepares me for another still more 
serious alienation, which will be the alienation by others" (p. 136). Merleau-Ponty thus stresses that the mirror instigates a rupture in my own being. Calling into mind the myth of Narcissus, the mirror causes an unbridgeable distance: Narcissus will never reach his object of love, his own mirror image.

Contrary to Husserl, Merleau-Ponty in this way provides a notion of selfrecognition that is not only constituted in "hereness". There are at least two related reasons for this difference in conception. First, the clear-cut distinction between "here" and "there" in Husserl's explanation of the appearance of another can be understood on the basis of his description of touch as an isolated sensory modality. Indeed, if touch is isolated from other sensory information it produces localized sensations, localizing my body "here" and nowhere else. Merleau-Ponty, on the contrary, allows for multisensory integration when he states that we need to give up the "crude delimitation" of the senses (1964, p. 133). His descriptions-such as a "palpation with the look" (1964, p. 134) or the palpation of the eye as a "remarkable variant" of tactile palpation (1964, p. 133) — are not meant in a metaphorical way, but refer to actual integration of the senses. This is the reason why Merleau-Ponty's analysis of touch fundamentally differs from Husserl's (Slatman 2005). According to the latter, touching and being touched melt together into a sensing (Empfindnis), while the former indicates that this relation, although reversible, does not imply a coincidence, but rather a difference (écart), as is the case in seeing and being seen. Husserl's zero-point is thus reinterpreted as the "difference" or "hiatus between one's right hand touched and one's left hand touching" (Merleau-Ponty 1964, p. 148).

Second, as a result of this, we could say that Merleau-Ponty, although he does not explicitly draw on these Husserlian terms, calls attention to the fact that the constitution of Leib presupposes the difference between Leib and Körper. He thus underscores the Leib's contamination with Körperlichkeit, i.e. spatial extension, and this ultimately means that something like "original presentation" (Urpräsenz) always already implies its opposite; it always entails something that is not originally present: "This universality of the sensible = Urpräsentation of what is not Urpräsentierbar" (1964, p. 218-219). It is therefore not unexpected that Merleau-Ponty in his essay in memory of Husserl, "The philosopher and his shadow" (1960)—which starts with the remark that "any commemoration is also a betrayal" (p. 159)-deliberately changes the latter's theory of Urpräsenz and Appräsenz (or Kompräsenz).

In this article, Merleau-Ponty explains that the constitution of one's own body implies a two-layered or split ontology, i.e. one's body as a physical thing (what Husserl had called Körper) and one's body as a "perceiving object" (what Husserl had called Leib). Subsequently, Merleau-Ponty claims that this difference equally underlies the constitution of surrounding others: "My right hand was present at the advent of my left hand's active sense of touch. It is in no different fashion that the other's body becomes animate before me when I shake another man's hand or just look at him" (1960, p. 168, my emphasis). Taken out of its context, this passage may induce us to believe that Merleau-Ponty equalizes self-recognition and recognition of another. The phrase "in no different fashion", however, does not refer to the act of recognition, but rather to the fact that any animated being or "sensibility" (Empfindbarkeit) essentially involves the double-sidedness of the body, viz. its being Leib and Körper. When I meet someone else, in shaking her hand, I will obviously not experience her Leib in the way I experience my own, but I do perceive 
her "in the flesh" (leibhaft), precisely because the other's perceived body "reflects my own incarnation" (Merleau-Ponty 1960, p. 167).

As I see it, this "incarnation" of one's self implies an extension or externalizing of the Leib's presumed zero-point. This is in line with Merleau-Ponty's conception of Kompräsenz (or Appräsenz). Contrasting sharply with Husserl, he claims that "copresence" applies to both one's own animated body and another's animated body. Put in this way, the experience of one's own Leib does not simply imply original presence of oneself to oneself. Self-recognition thus presupposes appresentation: appearing to myself I am not completely present to myself. I am co-present to myself. Only by means of this co-presentation or appresentation can I perceive myself as one. 'My two hands 'coexist' or are 'co-present' because they are one single body's hands. The other person appears through an extension of that copresence" (Merleau-Ponty 1960, p. 168). Abandoning the difference between Urpräsenz and Appräsenz or Kompräsenz, Merleau-Ponty provides a different idea of recognition of another: the appearance of myself and the appearance of another are not radically opposed to each other.

In the previous section, I have put forward the idea that intersubjectivity is intrinsically related to horizontal intentionality. To stress the differences between Husserl's and Merleau-Ponty's conception of recognition of another it will be helpful to take into account their respective conceptions of horizontality. According to Husserl, consciousness remains the foundation for the constitution of oneself, the other and a meaningful and objective world. Corresponding to this, horizontality involves the way consciousness operates: adumbrations or shadows imply, in fact, consciousness's incapacity to capture an entire present world, as opposed to its own original presence. Merleau-Ponty alters this idea of horizontality as he makes very explicit: "When Husserl spoke of the horizon of things...it is necessary to take the term seriously...it is a new type of being, a being by porosity, pregnancy, or generality, and he before whom the horizon opens is caught up, included in it. His body and the distances participate in one same corporeity" (Merleau-Ponty 1964, p. 148-149). Horizontality is not something of consciousness, but rather something of the world.

The point of departure for Merleau-Ponty's phenomenology is thus no longer consciousness, but rather the peculiar fabric of what he calls the flesh (la chair), which is a "mirror phenomenon" (Merleau-Ponty 1964, p. 255). The notion of the flesh seems to allude immediately to the realm of the tangible. Indeed, if we think of something incarnated, we think of something that can be touched or grasped. At least, it is the opposite of the intangible, of what evaporates. According to MerleauPonty, however, flesh is not just some material thing that can be touched. He calls it an "incarnated principle"-something between a thing and an idea — or an "element" (VI, 139). Flesh is an "ultimate notion", it is "not the union or compound of two substances, but thinkable in itself" (VI, 140). This suggests a certain monism. Of course, it is true that Merleau-Ponty uses the notion of flesh to overcome dualism. However, if we considered his philosophy as a rehabilitation of monism, flesh could not be understood as a single and identical substance. Instead of being a thing, it stands for a relation: a relation with itself (rapport à soi-même). Moreover, it is a relation with itself without coinciding with itself. "Flesh" thus refers to the principle of difference or écart. It indicates that there can be no presence without absence, 
which accords to the basic structure of horizontality: the visible presupposes the invisible, and the present experience of one's Leib can only come into being by means of an appresentation through one's Körper-perception.

On the basis of this, Merleau-Ponty interprets Einfühlung as something that precedes the clear-cut distinction between self and other: "Before the other is, the things are such non-beings, divergences-There is an Einfühlung and a lateral relation with things no less than with the other" (1964, p. 180). He also writes that Einfühlung is like the relation between the (percevant) perceiver and the perceived (perçu) (p. 248), indicating that it is fundamentally about the difference (écart) inherent to bodies that are capable of being stimulated and thus both Leib and Körper. In that sense, recognition of another refers to the possibility of recognizing someone else based upon the fact that we share the fabric of the flesh, which means that we all are both Leib and Körper. But first of all, we encounter each other in a world that in itself also bears an écart due to its inherent horizontality, i.e. the difference between presence (the visible) and absence (the invisible). Appresentation is thus operational in perceiving the world, in recognition of another as well as in self-recognition.

The difference between Husserl's and Merleau-Ponty's conception of intersubjectivity can be summarized in the following way. Whereas Husserl argues that intersubjectivity is a warrant for the existence of an objective world, Merleau-Ponty argues that intersubjectivity is supported by a "wild world", which, as a result of its open structure (because the Urpräsentierbarkeit of the flesh implies always something that is not primally present) is in essence open for multiple perspectives. ${ }^{6}$ In fact, the difference between their respective theories amounts to a difference in their conception of the "world". Merleau-Ponty describes it as wild, pre-reflective, a world that precedes individual consciousness and is thus characterized by "transitivism" and "syncretism" (Merleau-Ponty 1964, p. 221). According to Husserl, the world receives its sense and meaning from consciousness. His world still entails a certain center, which, additionally, is the only thing in this world that can be experienced as originally present.

Despite these differences, I believe that both Merleau-Ponty's and Husserl's theories of intersubjectivity are based upon the assumption of a shared world. For that reason, I do not completely agree with De Preester (2005) who claims that Merleau-Ponty's and Husserl's theories are opposed to each other, maintaining that the latter is founded on the mediating term of a "common body" whereas the former takes a "common object" as its mediating term. She seems to interpret Husserl's idea of Paarung in terms of an identification between observer and observed. As I have explained above, Paarung is not about identification in the sense of $\mathrm{X}=\mathrm{Y}$, and what is more, his idea of intersubjectivity is, like Merleau-Ponty's, fundamentally anchored in the possibility of sharing a world. Considering intersubjectivity Husserl's and Merleau-Ponty's view are not incompatible. If we look at the phenomenon of self-recognition, however, we see a sharp contrast between them. ${ }^{7}$

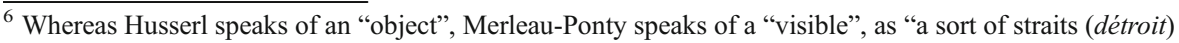
between exterior horizons and interior horizons ever gaping open (toujours béants)" (1964, p. 132).

${ }^{7}$ Essential to this difference is that Merleau-Ponty rejects the notion of Urpräsenz, whereas Husserl still presupposes the possibility of an original presentation to oneself. This is, in fact, in line with De Preester's claim that Husserl's philosophy remains a "philosophy of presence".
} 


\section{Identification in self-recognition and in recognition of another}

Having learnt from recent neuroscientific studies that the integration of sensory input is crucial for one's sense of body ownership we must conclude that Husserl's phenomenological description of the experience of oneself in Leib constitution is not sufficient. The RHI shows that the localized sensations are transferred to another location by means of vision. Or to phrase it differently, internally felt information of one's own body is transformed on the basis of visual information. The sense of body ownership presupposes the integration of touch, proprioception and vision. The RHI makes very clear that "the spatial content of tactile sensation relies more on vision than on proprioception" (De Vignemont 2007, p. 438). Vision is the sense of space par excellence: it provides information about things that are extended in space and not about a presumed zero-point devoid of perspective and adumbrations. Phenomenologically speaking, visual experience underlines the horizontal aspect of perception and hence its essential incompleteness; indeed, vision, most obviously, always implies appresentation. Since vision seems to be a crucial factor in (manipulating) one's sense of body ownership, as the RHI suggests, I think that it is possible to re-interpret the meaning of self-recognition in terms of visual or imaginary identification. This implies, as I will explain on the basis of MerleauPonty's later work, that self-recognition entails identification with something extended and thus something that appears according to appresentation.

Rejecting the difference between Appräsenz and Urpräsenz, Merleau-Ponty, unlike Husserl, emphasizes that one's experience or recognition of one's self does not involve coincidence. While experiencing myself, I do not simply coincide with (the sum of) localized sensations. To describe this non-coincidence with one-self, which brings about self-recognition, Merleau-Ponty conjures up again, not unintentionally, the figure of Narcissus:

It sees itself seeing; it touches itself touching; it is visible and sensitive for itself. It is a self, not by transparency, like thought, which never thinks anything except by assimilating it, constituting it, transforming it into thought-but a self by confusion, narcissism, inherence of the see-er in the seen, the toucher in the touched, the feeler in the felt - a self, then, that is caught up in things, having a front and a back, a past and a future...(Merleau-Ponty 1961, p. 124).

I interpret this passage in the following way. Self-recognition does not merely involve internal information, which as such is hard to locate incorrectly, but also information concerning one's extended existence: one's being seen, being touched and being felt. Self-recognition thus also entails the recognition of a certain shape or contour of oneself. One appears to oneself, like Narcissus, through one's own specular image. Recognizing oneself implies recognizing one's körperliche existence such as it may appear in one's mirror image. I would therefore say that self-recognition is not an immediate experience of oneself (as Husserl would have it), but rather it requires a mediation through a certain imaging of oneself by means of which one appears according to the mode of appresentation.

Since both presuppose appresentation, self-recognition, like recognition of another, involves a certain mediation. For that reason, one might suspect that 
Merleau-Ponty's philosophy does not provide clear criteria for distinguishing between self and other, or between self-recognition and recognition of another. ${ }^{8}$ However, I would like to suggest here that despite the intertwining of self, other and world, we can still differentiate between recognizing oneself through appresentation and recognizing another through appresentation. Only the first form of recognition entails self-attribution, which is enabled by a process of identification. This is clearly described in the text where Merleau-Ponty discusses a counter-example: a "Cartesian" who does not attribute his own mirror image to himself. A Cartesian "does not see himself in the mirror; he sees a puppet, an 'outside'...the mirror image is in no sense a part of him" (1961, p. 131, emphasis in original). Merleau-Ponty criticizes this view and maintains that one's mirror image is not solely a representation of one's "outside", but it is also part of oneself because one identifies with it. Such an identification process, $\mathrm{X}$ being equal with $\mathrm{Y}$, is lacking in a "Cartesian", who may only judge (or infer) that the resembling image is his own." And as psychoanalysis has taught us, identification not only indicates an equation of myself and my image, but also involves assimilation into it (Lacan 1949): I am my mirror image though I do not totally coincide with it. We could therefore say that this assimilative identification renders self-recognition, up to a certain degree, deceptive. This is exactly the reason why an illusion as the RHI can be so easily generated. Also, the fact that subjects may experience the rubber hand as if it were their own, which means that they know it is not their own but nevertheless they experience it as such, indicates that self-attribution may even include explicit self-delusion.

As I see it, it is especially the possibility of illusion which, from a phenomenological point of view, marks the distinction between self-recognition and recognition of another. Whereas the possibility of illusion is essential to self-recognition, recognition of another does not involve illusions and confusions concerning one's "here" and "there". Mirroring oneself, like Narcissus, one might not always realize immediately that one perceives oneself. This kind of mirroring often produces illusions and misinterpretations. This is aptly described by Ernst Mach: while entering a bus he suddenly sees a face and wonders "who is that pathetic teacher (heruntergekommener Schulmeister) entering the bus", not immediately realizing that he was facing his own mirror image (Cf. Waldenfels 2000, p. 32). This confusion is the result of our lived body, being both "here" and "there", being both Leib or localized experience without perspective, and Körper or thing with adumbrations. Incarnation or the body's flesh indicates precisely the extension of a zero-point. ${ }^{10}$

\footnotetext{
${ }^{8}$ Lefort (1990), for instance, argues that Merleau-Ponty's philosophy can do no justice to the irreducible character of alterity.

${ }^{9}$ One could say that Descartes' idea of recognition of another accords with what Erdmann later calls Einfühlung on the basis of a theoretical inference according to analogy (Dastur 1995). For instance, this is clear in the famous passage from the second Meditation, in which Descartes claims that while looking out of his window, he only perceives hats and coats. From this he infers that there might be humans underneath them. In the same way, the recognition of one's own mirror image is based upon this kind of theoretical inference or judgment.

${ }^{10}$ This is what Nancy (2006) calls the body's espacement or exposition. Although he claims to discard Merleau-Ponty's phenomenology, I think that Nancy's description of one's own body in the sense of a "corpus", a being that bears a difference in itself, that exceeds itself and exposes itself, perfectly matches the idea of the flesh as the unity of and the difference between Leib and Körper.
} 
The appearance of another is a "reflection of my own incarnation", yet this leibhaft appearance is unmistakably always "there", never "here". Even if I identify with someone - if I want to be like this person and subsequently incorporate his or her features, and if I unwittingly imitate this person, knowing immediately the meaning and goal of his or her gestures and behavior-I do not incorporate this person. I do not assimilates his or her "there" to my "here". It results from this, perhaps rather counter intuitively, that one's own appearance involves more confusion and less certainty than the appearance of another.

In this paper I have analyzed the difference between recognition of another and selfrecognition while referring to illusory experiences of oneself. Throughout my argument, I have referred to various experiences which one may wish to summarize as follows: (1) the experience as someone/something other as other; (2) the experience of something other as own (as in the RHI); and (3) the experience of one's own body as own. I have argued that the difference between (1), on the one hand, and (2) and (3), on the other, consists of the difference between "thereness" (1) and "thereness" which can be localized "here" (2 and 3). Although I hold the view that we can clearly distinguish between (1) and (2 and 3), I believe that a clear cut distinction between (2) and (3) is, in fact, untenable. Since the experience of one's own body (3) implies both a nonintentional Leib experience and a Körper experience, (which, indeed, will be amplified when visual input - emphasizing appresentation in perception-is at play), the possibility that (3) and (2) blur is always imminent.

One may want to argue here that precisely because the experience of one-self involves both the of Leib and Körper, the distinction between (1) and (2) can blur as well: the strange element, the dummy hand, is experienced as one's own, as Leib, but also as a Körper. And it is true that in the RHI the dummy hand is experienced as if it were one's own, thus including the knowledge that the hand is not one's own but something other. However, I would like to maintain that in this case the distinction between self-recognition and recognition of another is not abolished. The knowledge that the dummy hand is not one's own is based upon one's body image, and not upon the characteristic perceptual organization at stake in self-recognition.

This perceptual organization consists of the fact that what is seen ("there") can also be felt here (touch, proprioception). Including a mental image, but also beliefs and dispositions related to one's own body, one's body image involves more than the actual perception of one's body. Also its incorporation of strange elements is not necessarily based upon the sensory integration of touch, proprioception and vision. One may experience a tool as part of one's body image, but this does not imply that one experiences the tool as if it were a part of one's own body, as is the case in the RHI. In sum, it is because of the specific perceptual organization that a dummy hand can be experienced as own, and one identifies with it while relating it to preceding embodied self-experience, i.e. one's body image. This identification, however, not necessarily results in a transformation of the body image. And this implies that although the dummy hand may be experienced as one's own, by means of localized sensations, at the level of knowledge or beliefs, it is not experienced as one's own: hence the as if experience. While focusing on the perceptual organization of actual self-experiences, one cannot clearly distinguish-from a phenomenological perspective - the experience of something strange as one's own from the experience of something own as own. 


\section{Conclusion}

In this paper I have made an effort to phenomenologically describe the phenomenon of the RHI, while drawing on Husserl's and Merleau-Ponty's work. Since the RHI implies an incorporation of something strange it may be tempting to interpret this illusionary self-recognition in terms of a rudimentary form of empathy or recognition of another. My main objective, however, was to highlight the difference between these two forms of recognition. I have argued that Husserl's phenomenology, while emphasizing the difference between original presentation (Urpräsenz) in selfrecognition and appresentation (Appräsenz) in recognition of another, results in a clear distinction between identification in the sense of $\mathrm{X}=\mathrm{Y}$ and identification as $\mathrm{X} \neq \mathrm{Y}$. And yet his theory is not entirely satisfactory because he also claims that selfrecognition presupposes an immediate presentation to oneself. In so doing he neglects the very fact that self-recognition equally presupposes appresentation. I have argued that Merleau-Ponty's later work can be useful in understanding this aspect of externalization in self-recognition.

In my reading of the RHI-experiment, I have made clear that self-recognition presupposes multisensory integration ruled by a top-down identification process. This is a flexible process, responsible for what I have called the "possibility of illusion." Whereas self-recognition may involve an illusion concerning one's "here" and "there", one recognizes another only as someone "there". It is because one shares "thereness" that it is possible to immediately understand one another. Before recognizing the other as someone with a similar physical and mental constitution, one recognizes the other as someone with whom one shares a meaningful world. It is probable that sharing a world of action and perception is motivated by the activation of mirror neurons. Phenomenologically, a shared world is based upon horizontality, either as inherent in the operation of consciousness (Husserl), or as inherent in the world's visibility (Merleau-Ponty).

Open Access This article is distributed under the terms of the Creative Commons Attribution Noncommercial License which permits any noncommercial use, distribution, and reproduction in any medium, provided the original author(s) and source are credited.

\section{References}

Armel, K. C., \& Ramachandran, V. S. (2003). Projecting sensations to external objects: Evidence from skin conductance response. Proceedings of the Royal Society of London: Biological, 270, 1499-506.

Botvinick, M. (2004). Probing the neural basis of body ownership. Science, 305, 782-83.

Botvinick, M., \& Cohen, J. (1998). Rubber hands 'feel' touch that eyes see. Nature, 391, 756.

Costantini, M., \& Haggard, P. (2007). The rubber hand illusion: Sensitivity and reference frame for body ownership. Consciousness and Cognition, 16, 229-40.

Dastur, F. (1995). Husserl. Des mathématiques à l'histoire. PUF: Paris.

De Preester, H. (2005). Two phenomenological logics and the mirror neurons theory. In H. De Preester \& V. Knockaert (Eds.), Body image and body schema, pp. 45-64. Amsterdam: John Benjamins Publishing Company.

De Vignemont, F. (2007). Habeas corpus: The sense of ownership of one's own body. Mind \& Language, $22,427-49$. 
Depraz, N. (1995). Transcendance et Incarnation. Le statut de l'intersubjectivité comme altérité à soi chez Husserl. Vrin: Paris.

Depraz, N. (1997). La traduction du 'Leib': Une Crux Phaenomenologica. Études phénoménologiques, 26, 91-109.

Ehrsson, H. H., Holmes, N. P., \& Passingham, R. E. (2005). Touching a rubber hand: Feeling of body ownership is associated with activity in multisensory brain areas. Journal of Neuroscience, 25, 10564-73.

Ehrsson, H. H., Spence, C., \& Passingham, R. E. (2004). That's my hand! activity in premotor cortex reflects feeling of ownership of a limb. Science, 305, 875-77.

Gallagher, S. (2005). How the body shapes the mind. Oxford: Oxford University Press.

Gallagher, S. (2007). Simulation trouble. Social Neuroscience, 2, 353-65.

Gallese, V., Fadiga, L., Fogassi, L., Rizzolatti, G. (1996). Action recognition in the premotor cortex. Brain, 119, 593-609.

Husserl, E. (1931). Cartesian meditations. Translation by Cairns, D., 1970. The Hague: Martinus Nijhoff.

Husserl, E. (1950). Ideen zu einer reinen Phänomenologie und phänomenologischen Philosophie. Erstes Buch. Husserliana III. The Hague: Matinus Nijhoff.

Husserl, E. (1952). Ideas pertaining to a pure phenomenology and to a phenomenological philosophy, Second book. Translation by Rojcewicz, R. and Schuwer, A., 1989. Dordrecht/Boston/London: Kluwer Academic Publishers.

Husserl, E. (1973a). Zur Phänomenologie der Intersubjektivität I (1905-1920). Husserliana XIII. The Hague: Martinus Nijhoff.

Husserl, E. (1973b). Zur Phänomenologie der Intersubjektivität II (1921-1928). Husserliana XIV. The Hague: Martinus Nijhoff.

Keysers, C., Wicker, B., Gazzola, V., Anton, J.-L., Fogassi, L., Gallese, V. (2004). A touching sight: SII/ PV activation during the observation and experience of touch. Neuron, 42, 335-46.

Lacan, J. (1949). Le stade du miroir comme formateur de la fonction du Je, pp. 92-99. In Écrits I. Seuil: Paris.

Lefort, C. (1990). Flesh and Otherness. In G. A. Johnson \& M. B. Smith (Eds.), Ontology and alterity in Merleau-Ponty. Evanston: Northwestern University Press.

Legrand, D. (2006). The bodily self: The sensori-motor roots of pre-reflective self-consciousness. Phenomenology and the Cognitive Sciences, 5, 89-118.

Meijsing, M. (1998). Person and perspective. On the role of first and third person perspective in personhood and personal identity. In T. Derksen (Ed.), The promise of evolutionary epistemology. Tilburg: Tilburg University Press.

Merleau-Ponty, M. (1951). The child's relations with others, pp. 96-155. Northwestern University Press: In The Primacy of Perception. Evanston.

Merleau-Ponty, M. (1960). The philosopher and his shadow, pp. 159-81. Northwestern University Press: In Signs. Evanston.

Merleau-Ponty, M. (1961). Eye and mind. In B. Smith (Ed.), The Merleau-Ponty aesthetics reader. Philosophy and painting 1993. Evanston: Northwestern University.

Merleau-Ponty, M. (1964). The visible and the invisible. Translation by Lingis, A., 1968. Evanston: Northwestern University Press.

Murray, C. D. (2004). An interpretative phenomenological analysis of the embodiment of artificial limbs. Disability and Rehabilitation, 26, 963-73.

Nancy, J.-L. (2006). Corpus. Paris: Édition Métaillié.

Petit, J.-L. (2003). On the relation between recent neurobiological data on perception (and action) and the Husserlian theory of constitution. Phenomenology and the Cognitive Sciences, 2, 281-98.

Ramachandran, V. S., \& Hirstein, W. (1998). The perception of phantom limbs. Brain, 121, 1603-30.

Rizzolatti, G., Fogassi, L., \& Gallese, V. (2000). Cortical mechanisms subserving object grasping and action recognition. A new view on the cortical motor functions. In M. S. Gazzaniga, et al. (Eds.), The cognitive neurosciences, pp. 539-52. Cambridge, MA: MIT Press.

Schilder, P. (1935). The image and appearance of the human body. London/New York: International University Press.

Shoemaker, S. (1968). Introspection and the self. Midwest Studies in Philosophy, X, pp. 101-20.

Slatman, J. (2005). The sense of life: Husserl and merleau-ponty on touching and being touched. Chiasmi International, 7, 305-25.

Tsakiris, M., \& Haggard, P. (2005). The rubber hand illusion revisited: Visuotactile integration and selfattribution. Journal of Experimental Psychology: Human Perception and Performance, 31, 80-91. 
Waldenfels, B. (1989). Körper-Leib. In J. Leenhardt \& R. Picht (Eds.), Esprit/Geist. 100 Schlüsselbegriffe für Deutsche und Franzosen, pp. 342-45. Piper: München.

Waldenfels, B. (2000). Das leibliche Selbst. Suhrkamp Verlag: Vorlesungen zur Phänomenologie des Leibes. Frankfurt am Main.

Zahavi, D. (1997). Horizontal intentionality and transcendental intersubjectivity. Tijdschrift voor Filosofie, 59, 304-21.

Zahavi, D. (2001). Beyond empathy. Phenomenological approaches to intersubjectivity. Journal of Consciousness Studies, 8, 151-67. 